\title{
Temperature sensitivity of soil respiration and its effects on ecosystem carbon budget: nonlinearity begets surprises
}

\author{
Ye $\mathrm{Qi}^{\mathrm{a}, \mathrm{b}, *}$, Ming $\mathrm{Xu}{ }^{\mathrm{b}}$, Jianguo $\mathrm{Wu}^{\mathrm{c}}$ \\ ${ }^{a}$ Institute of Environmental Science, Beijing Normal University, Beijing 100875, China \\ ${ }^{\mathrm{b}}$ Department of Environmental Science, Policy and Management, University of California-Berkeley, Berkeley, CA 94720-3312, USA \\ ${ }^{\mathrm{c}}$ Department of Plant Biology, Arizona State University, Tempe, AZ 85287-1601, USA
}

\begin{abstract}
Nonlinearity is a salient feature in all complex systems, and it certainly characterizes biogeochemical cycles in ecosystems across a wide range of scales. Soil carbon emission is a major source of uncertainty in estimating the terrestrial carbon budget at the ecosystem level and above. Due to the lack of consideration of the nonlinearity in temperature sensitivity of soil respiration, several commonly used ecosystem models produce substantially different estimates of soil respiration with the same or similar model input. In this paper we demonstrated that the response of soil respiration to changes in temperature sensitivity is nonlinear and, thus, that the oversimplified formulations may significantly reduce the accuracy of ecosystem models in predicting carbon fluxes. To alleviate this problem, we have developed a general model of temperature sensitivity of soil respiration that explicitly considers this nonlinearity. The model was supported by our field measurements from a forest ecosystem, and used to assess the uncertainty in estimating the soil $\mathrm{CO}_{2}$ efflux with several commonly used ecosystem models. Our results indicated that the variations and nonlinearity of the soil respiration-temperature relationship and its dependence on moisture may have important implications for ecosystem carbon modeling at regional and global scales. In other words, 'small causes' may lead to 'large effects' in complex ecosystems in terms of carbon dynamics. In particular, when the variability in temperature sensitivity of soil respiration was incorporated in the several commonly used ecosystem models, the carbon source-sink relationship for terrestrial ecosystems under future global warming scenarios became dramatically different from those reported previously. Thus, we advocate that confidence limits are both necessary and feasible for simulated carbon budget from ecosystem models. Based on field measurements and model simulations, our study provides useful information for computing such confidence limits. In addition, our new model of temperature sensitivity of soil respiration seems more general and yet realistic, and can improve the accuracy of ecosystem models in predicting carbon fluxes at large scales. (c) 2002 Elsevier Science B.V. All rights reserved.
\end{abstract}

Keywords: Temperature sensitivity of soil respiration; Ecosystem modeling; Carbon flux; Nonlinearity in biogeochemistry; $Q_{10}$

\section{Introduction}

* Corresponding author. Tel.: + 1-510-643-0259; fax: +1510-643-2504.

E-mail address: yqi@nature.berkeley.edu (Y. Qi).

Nonlinearity, emergent properties, and hierarchical linkages are among the most salient fea- 
tures of complex systems such as ecological systems (Nicolis and Prigogine, 1989; Wu and Loucks, 1995; Wu, 1999). Biogeochemical cycling is an extremely complex and fundamentally important ecological process that takes place across a range of scales in time and space. In modeling ecosystem carbon dynamics, one of the important, but not yet adequately addressed nonlinear relationships is the temperature sensitivity of soil respiration. Soil respiration usually refers to a suite of complex processes contributing to carbon dioxide $\left(\mathrm{CO}_{2}\right)$ efflux from the surface of soils. These processes include respiration by plant roots, microorganisms and soil fauna, and decomposition of soil organic matter. Despite the complexity of the processes, soil respiration has been modeled with simple empirical equations in ecosystem models. These simple models of soil respiration are derivatives of the exponential chemical reaction-temperature equation originally developed by Van't Hoff (1898):

$R=R_{\mathrm{c}} Q_{10^{10}}^{\frac{T-T_{\mathrm{c}}}{10}}$

where, in the case of soil respiration, $R$ and $R_{\mathrm{c}}$ are the respiration rates $\left(\mu \mathrm{mol} \mathrm{C} \mathrm{m}{ }^{-2} \mathrm{~s}^{-1}\right)$ at temperature $T$ and $T_{\mathrm{c}}$, respectively. $Q_{10}$, is an empirically fitted parameter, representing the relative increase $\left(R / R_{\mathrm{c}}\right)$ as temperature increases by $10{ }^{\circ} \mathrm{C}$. Thus, $Q_{10}$ is a measure of the sensitivity of respiration rate to temperature variations. The above equation is often called 'the $Q_{10}$ model'. It is actually a different form of exponential equation. An alternative formulation of the $R-T$ relationship is the Arrhenius equation:

$R=A \mathrm{e}^{-\frac{E_{\mathrm{o}}}{R_{\mathrm{o}} T}}$

where, $R$ is the respiration rate, $T$ is the absolute temperature in $\mathrm{K}, A$ is the Arrhenius coefficient, $E_{\mathrm{o}}$ is the activation energy for the chemical reaction, and $R_{\mathrm{o}}$ is the gas constant $\left(R_{\mathrm{O}}=8.314\right.$ $\mathrm{J} \mathrm{K}^{-1} \mathrm{~mol}^{-1}$ ).

Based on an extensive data set compiled from the literature, Lloyd and Taylor (1994) showed that the $Q_{10}$ model was biased when fitting to the data - underestimating at lower temperatures and overestimating at higher temperatures. While the
Arrhenius equation had a better fit than the $Q_{10}$ model, Lloyd and Taylor (1994) recommended a modified Arrhenius model, know as the Lloyd and Taylor equation:

$R=R_{\mathrm{c}} \mathrm{e}^{-\frac{E}{T-T_{\mathrm{c}}}}$

where $R_{\mathrm{c}}, E$ and $T_{\mathrm{c}}$ are fitted parameters (note that $E$ here does not denote the activation energy as in Eq. (2)). Lloyd and Taylor (1994) showed the modified Arrhenius equation had unbiased fit to the data they compiled.

Despite the problems with the $Q_{10}$ model, it has been widely used in modeling the process of soil respiration (Heimann et al., 1989; Raich et al., 1991; Running and Hunt, 1993; Schimel et al., 2000). Unlike the Arrhenius equation and its modified form by Lloyd and Taylor (1994), the $Q_{10}$ model relates the rate of soil respiration to varying temperature through a parameter, $Q_{10}$, which determines the rate of change of soil respiration with respect to temperature. This temperature sensitivity measure is useful for understanding ecosystem carbon dynamics in response to global climate change. A greater value of $Q_{10}$ means a higher respiration rate locally and globally for a given increase in temperature. Recent studies have shown that the value of $Q_{10}$ may vary considerably in space and time across systems (Raich and Schlesinger, 1992; Kirschbaum, 1995; Simmons et al., 1996; Kirschbaum, 2000). Based on an extensive literature survey of soil respiration studies, Raich and Schlesinger (1992) found that the value of $Q_{10}$ varied from 1.3 to 3.3. To avoid confounding effects with other factors such as soil moisture and litter quality, Kirschbaum (1995) selected laboratory-based measurements only, but obtained an even greater range of $Q_{10}$ from 2.5 at $20{ }^{\circ} \mathrm{C}$ to 8 at $0{ }^{\circ} \mathrm{C}$. Although it has been well documented that $Q_{10}$ varies with temperature, this parameter has commonly been treated as a constant in ecosystem models (Heimann et al., 1989; Raich et al., 1991; Running and Hunt, 1993; Potter et al., 1993; Schimel et al., 2000). Due to the nonlinear nature of the relationship between $Q_{10}$ and respiration, small changes in $Q_{10}$ may cause significant differences in estimated soil respiration fluxes 
(Townsend et al., 1992; Holland et al., 1995; Kutsch and Kappen, 1997). Therefore, accurately quantifying $Q_{10}$ and its variability is critical for obtaining a reliable estimate of ecosystem carbon budget and its uncertainty bounds.

Besides temperature, soil moisture is another important factor affecting the rate of soil respiration (Singh and Gupta, 1977; Davidson et al., 1998; Gulledge and Schimel, 2000; Xu and Qi, 2001a). Numerous studies have sought to establish a relationship of soil respiration rate with soil moisture and temperature (e.g. Schleser, 1982; Lloyd and Taylor, 1994; Thierron and Laudelout, 1996; Davidson et al., 1998; Gulledge and Schimel, 2000; Xu and Qi, 2001a). However, up to date it is still unclear how $Q_{10}$ is affected by factors other than temperature (Carlyle and Than, 1988; Simmons et al., 1996). However, the effects of temperature and moisture on $Q_{10}$ are of critical importance in assessing the impacts of the changing climate on ecosystem carbon fluxes (Betts, 2000; Cox et al., 2000; Kirschbaum, 2000). Unfortunately, ecosystem models commonly used in global climate change studies have not explicitly considered the varying sensitivity of soil respiration rates to temperature and moisture. We argue that this may be a significant missing link in the current ecosystem models.

In this study, we first present a general model of the sensitivity of soil respiration to temperature and other abiotic and biotic factors, although we are concerned particularly with soil temperature and moisture. This simple, yet comprehensive, model is able to incorporate multiple factors that affect the temperature sensitivity of soil respiration, and can be used to synthesize the existing models of environmental controls on soil respiration. Then, we parameterize the model with measurement data obtained by the authors from a ponderosa pine forest in the Sierra Nevada Mountains in northern California, and demonstrate how this model works in practice. Finally, we use the model to investigate the range of variability in estimated carbon fluxes due to differential $Q_{10}$ values with several commonly used ecosystem models. An important question we ask here is whether these ecosystem models have significantly over- or under-estimated future soil car- bon emission because of their use of a constant $Q_{10}$.

\section{A general model of temperature sensitivity of soil respiration}

Let us assume that the rate of soil respiration $(R)$ is determined by temperature, $T$, and other physical and biological factors, $X=\left(x_{1}, x_{2}, \ldots, x_{n}\right)$ i.e. $R=f(T, X)$ or $R=f\left(T, x_{1}, x_{2}, \ldots, x_{n}\right)$. We further assume that any of these other factors can be a function of temperature, where $\mathrm{d} x_{i} / \mathrm{d} T=0$ denotes that $x_{\mathrm{i}}$ does not change with $T$, while $\mathrm{d} x_{i} / \mathrm{d} T \neq 0$ indicates the existence of a relationship of some sort between the two variables.

To take into account the dynamic nature of temperature sensitivity of soil respiration, we define $q$ as the relative instantaneous rate of change in soil respiration rate with respect to temperature i.e.

$q(T, X)=\frac{1}{R} \frac{\mathrm{d} R}{\mathrm{~d} T}$

From (Eq. (4)) and the definition: $Q_{10}(T, X)=$ $R(T+10, X) / R(T, X)$, we obtain the following relationship between $Q_{10}$ and $q$ :

$Q_{10}=\mathrm{e} \int_{T}^{T+10} q(\tau, X) \mathrm{d} \tau$.

In contrast with $Q_{10}$ which is the relative change of soil respiration over 10 degrees, $q(T, X)$ is directly related to the first derivative of the soil respiration function, and thus a more accurate measure of the temperature sensitivity than $Q_{10}$. It is evident from (Eq. (5)) that $Q_{10}$ is a monotonic function of $q(T, X)$, and that factors affecting $q$ also influence $Q_{10}$. We will focus on $q$ hereafter, but the conclusions should also apply to $Q_{10}$.

To derive the relationship between $q$ and related abiotic and biotic factors, let us decompose the rate of change in soil respiration with respect to temperature as follows:

$\frac{\mathrm{d} R}{\mathrm{~d} T}=\sum_{i=1}^{n} \frac{\partial f(T, X)}{\partial x_{i}} \frac{\mathrm{d} x_{i}}{\mathrm{~d} T}+\frac{\partial f(T, X)}{\partial T}$,

where $n$ is the number of elements in the $X$ vector. Thus, (Eq. (4)) now becomes: 
$q(T, X)=\frac{1}{R}\left(\sum_{i=1}^{n} \frac{\partial f(T, X)}{\partial x_{i}} \frac{\mathrm{d} x_{i}}{\mathrm{~d} T}+\frac{\partial f(T, X)}{\partial T}\right)$.

Using the concept of temperature sensitivity and our general model (Eq. (4)), we now can examine the differences among the various formulations of soil respiration. For Van't Hoff's $Q_{10}$ model, because $Q_{10}$ is a constant, from (Eq. (4)) we know that $q$ must also be a constant, which is equal to $\ln Q_{10} / 10$. For other models, $q$ is a function of temperature. In particular, $q(T)=E / R T^{2}$ in the Arrhenius equation; $q(T)=E /\left(T-T_{\mathrm{c}}\right)^{2}$ in the Lloyd-Taylor equation; $q(T)=b / a+b T$ in a linear soil respiration model where $a$ and $b$ are intercept and slope, respectively; and $q(T)=c / T$ in a power function model of soil respiration (Fig. 1).

Lloyd and Taylor (1994) pointed out that the $Q_{10}$ model was inappropriate for fitting the respiration-temperature function because it tends to overestimate the respiration rate at higher temperatures and underestimate it at lower temperatures. This problem is clearly illustrated in Fig. 1, showing that the temperature sensitivity of soil respiration may change significantly along a temperature gradient. Similarly, Kirschbaum (1995) plotted the $Q_{10}$ values against temperature based on data from laboratory experiments and derived an empirical function, $Q_{10}=\mathrm{e}^{10 \beta\left(1-T / T_{\mathrm{opt}}\right)}$. As discussed earlier, $q$ is a constant only in the $Q_{10}$ model, and it is temperature-dependent in all other alternative formulations listed in Fig. 1. In general, the temperature sensitivity is negatively correlated with temperature. At the midpoint of the temperature range that is used for fitting the equations, the value of $q(T)$ derived from all the alternative models tends to converge to the constant $q$ value obtained from the $Q_{10}$ model. However, the $q$ value begins to diverge quickly and significantly once away from the midpoint (Fig. 1). In addition, the curvature of these models differs considerably: the power function has the deepest curvature, followed by the Lloyd-Taylor function, the linear function, and the Arrhenius function. Apparently, the $Q_{10}$ model is only valid for a small range of temperature, but the alternative models can be used for a wider range of temperature because they take into account the varying temperature sensitivity of soil respiration.

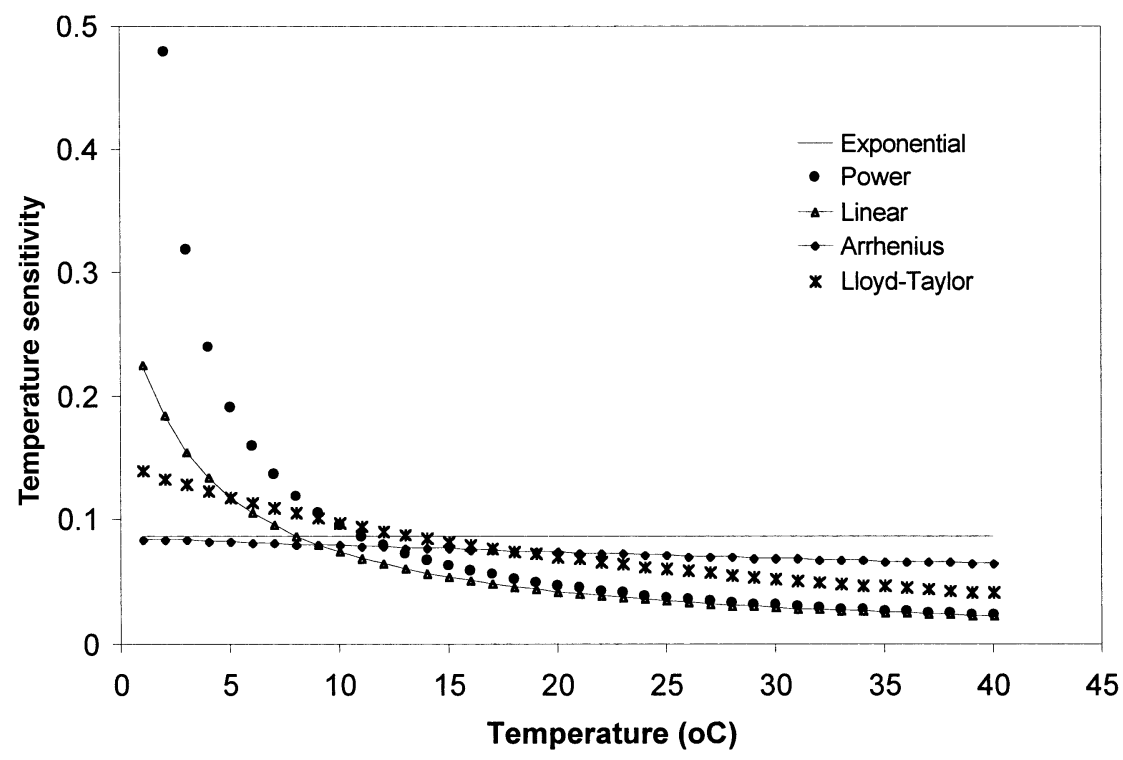

Fig. 1. Temperature sensitivity of soil respiration as a function of temperature, showing different curves derived from five soil respiration equations: Linear $(R=a+b T)$, exponential (Eq. (1)), Arrhenius (Eq. (2)), Lloyd and Taylor (Eq. (3)), and power $\left(R=R_{\mathrm{o}} T^{\mathrm{c}}\right)$. Data are taken from Lloyd and Taylor (1994). Parameters for linear and power functions are derived by fitting the Lloyd-Taylor equation. 


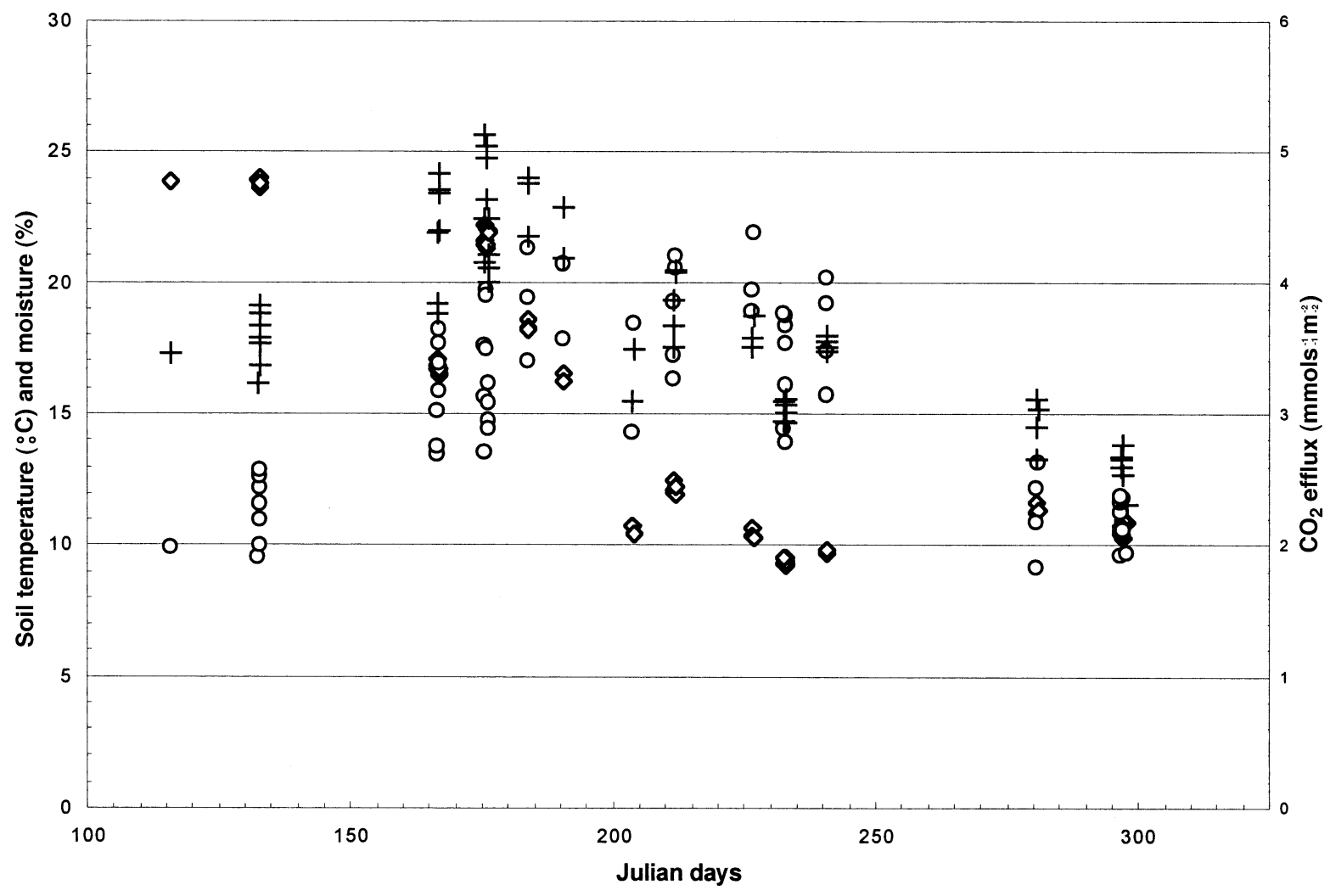

Fig. 2. Measurement results of soil $\mathrm{CO}_{2}$ efflux (cross), temperature at $10 \mathrm{~cm}$ in depth (circle) and volumetric moisture (diamond, \% $\mathrm{m}^{3} / \mathrm{m}^{3}$ ). The measurements were taken at Blodgett Forest in Northern California from June 1998 through August 1999. Each data appoint represents an average of 18 sampling points. In general, soil $\mathrm{CO}_{2}$ efflux increases with temperature but decreases with moisture. Soil moisture and temperature together determine the magnitude of soil $\mathrm{CO}_{2}$ efflux.

\section{Effects of soil moisture on the temperature sensitivity of soil respiration}

As indicated in our general model (Eqs. (4) and (7)), the temperature sensitivity may be affected by abiotic and biotic factors other than temperature. Because these factors are spatially and temporally heterogeneous, variations of the temperature sensitivity are also expected in time and space. In the following we examine the effects of soil temperature and moisture on the temperature sensitivity of the soil respiration relationship using a data set from a long-term, systematic measurement program. Field measurements were conducted from June 1998 through August 1999 in a young ponderosa pine forest adjacent to the
Blodgett Forest Research Station (38 53'42.9"N, $120^{\circ} 37^{\prime} 57.9^{\prime \prime} \mathrm{W}$, elevation of $1315 \mathrm{~m}$ ), a research forest of the University of California, Berkeley. We measured the soil $\mathrm{CO}_{2}$ efflux, soil temperature at $10 \mathrm{~cm}$ below the surface, and the volumetric moisture of the top soil layer $(30 \mathrm{~cm}$ in depth) at 18 sampling locations that were regularly spaced with $10 \mathrm{~m}$ apart. Fig. 2 shows the data from these field measurements, in which the variability of the soil carbon efflux in relation to temperature and moisture is evident. Xu and Qi (2001a) provided further details of the research site, instrumentation, and measurement procedures.

Through a bivariate regression analysis, we have derived the following relationship between the soil $\mathrm{CO}_{2}$ efflux and two environmental factors, soil temperature and moisture: 
$R=0.2439 M^{0.4199} T^{0.5581} \quad\left(n=36, r^{2}=0.89\right)$,

where $T$ is soil temperature $\left({ }^{\circ} \mathrm{C}\right), M$ is soil moisture $\left(\mathrm{m}^{3} / \mathrm{m}^{3}, \%\right), \quad R$ is soil $\mathrm{CO}_{2}$ efflux $\left(\mu \mathrm{mol} \mathrm{m} \mathrm{m}^{-2} \mathrm{~s}^{-1}\right)$. From this regression equation, we were able to calculate the temperature sensitivity of $R$ using (Eq. (7)) as follows:

$q(T, M)=\frac{0.4199}{M} \frac{\mathrm{d} M}{\mathrm{~d} T}+\frac{0.5581}{T}$.

$\mathrm{Xu}$ and Qi (2001b) derived a relationship between $T$ and $M$ with the form of $T=63.6-2.2 M$ for this particular forest ecosystem (Fig. 5 in $\mathrm{Xu}$ and Qi (2001b)). This relationship can be used to determine the rate of change in $M$ with respect to $T: \mathrm{d} M / \mathrm{d} T=-1 / 2.2=-0.455$. Thus, Eq. (8) becomes

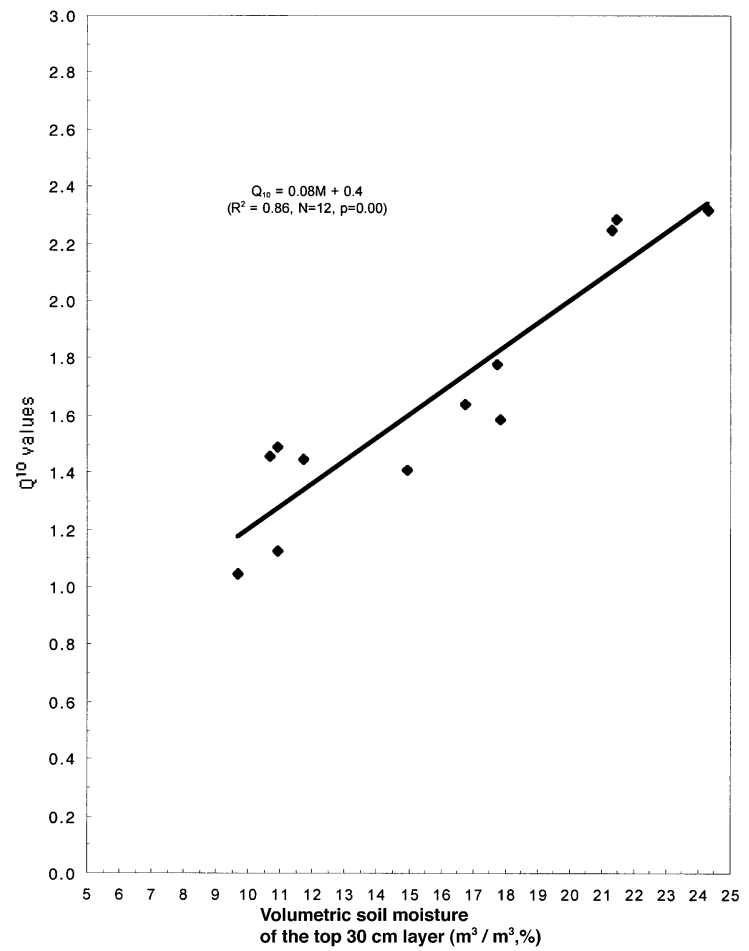

Fig. 3. The relationship between $Q_{10}$ and soil volumetric moisture $\left(\%, \mathrm{~m}^{3} / \mathrm{m}^{3}\right)$. Data were from the measurements of soil $\mathrm{CO}_{2}$ efflux and moisture at Blodgett Forest in Northern California from June 1998 through August 1999. Each data point represents a monthly average of 18 sampling locations. The regression line indicates a linear relationship between $Q_{10}$ and soil volumetric moisture.

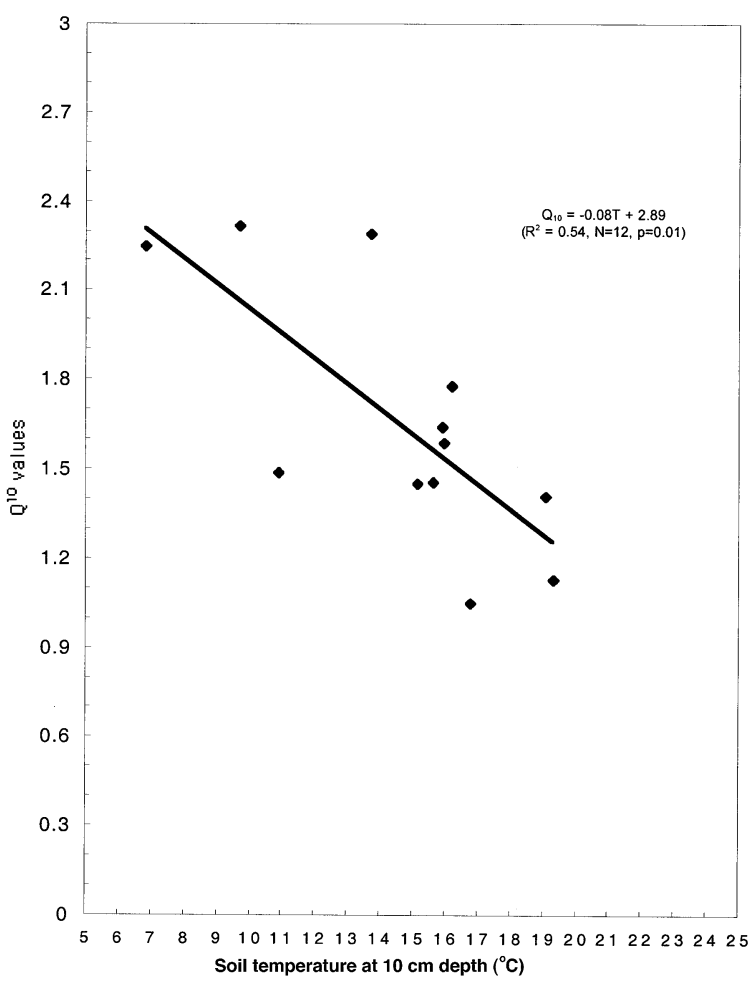

Fig. 4. The relationships between $Q_{10}$ and soil temperature at $10 \mathrm{~cm}$ below-ground. Data were from the same source as in Fig. 3. The relationship shows a negative linear correlation between $Q_{10}$ and soil temperature.

$q(T, M)=\frac{0.5581}{T}-\frac{0.1909}{M}$.

Eq. (10) implies that the relative temperature sensitivity, $q$, is determined by two factors, $T$ and $M$. From our regression analysis based on field measurements, it seems reasonable to consider temperature and moisture as two primary factors affecting $q$ (as Eq. (8) indicates the two factors explain $89 \%$ of the variance in soil carbon efflux). Specifically, $q$ decreases with soil temperature and increases with soil moisture. Our field measurements support this relationship (Figs. 3 and 4). (Eq. (10)) implies that the heterogeneous distribution of soil moisture and temperature will lead to spatiotemporal variability in temperature sensitivity, $q$. The $q$ value at each location can be calculated according to the values of soil moisture and temperature using (Eq. (10)), and $Q_{10}$ can be computed consequently using (Eq. (7)). Table 1 
summarizes the spatial variation of $Q_{10}$ among our 18 sampling locations. Fig. 5 shows the temporal variations of $Q_{10}$ in response to changes in soil temperature and moisture during the measurement period.

These measurements are admittedly of very limited scope because they are from only one forest ecosystem. The range of variations in the temperature sensitivity of soil respiration revealed here may be considered the minimum because there are many other types of ecosystems with disparate environmental settings and biological characteristics. Nevertheless, it is clear from these measurements that both temperature and moisture significantly affect $Q_{10}$, and ignoring the variability in $Q_{10}$ may lead to unjustifiable errors in predicting ecosystem carbon fluxes. In the next section, we will examine the magnitude of these errors in the context of global carbon budget using several most commonly used ecosystem models.

\section{Effects of variations in temperature sensitivity of soil respiration on ecosystem carbon budget}

As pointed out above, the temperature sensitivity of soil respiration is affected by soil temperature, soil moisture and other factors, and a constant value of temperature sensitivity ( $q$ or $Q_{10}$ ) can only be used, at best, within a limited range of variability for these factors. However, it has been a common practice in several most commonly used ecosystem models that temperature sensitivity of soil respiration is treated as invariant (e.g. Heimann et al., 1989; Raich et al., 1991; Running and Hunt, 1993; Potter et al., 1993). Table 2 lists the soil respiration equations and $Q_{10}$

Table 1

Comparison of $Q_{10}$ values among 18 sampling locations

\begin{tabular}{|c|c|c|c|c|c|}
\hline $\begin{array}{l}\text { Sampling } \\
\text { locations }\end{array}$ & $Q_{10}$ & $R^{2}$ & $\begin{array}{l}\mathrm{CO}_{2} \text { efflux } \\
\left(\mu \mathrm{mol} \mathrm{m} \mathrm{m}^{-2} \mathrm{~s}^{-1}\right)\end{array}$ & Temperature at $10 \mathrm{~cm}\left({ }^{\circ} \mathrm{C}\right)$ & Soil moisture (gravimetric $\%$ ) \\
\hline EP1 & 1.33 & 0.19 & 6.03 & 15.53 & 14.53 \\
\hline EP2 & 1.88 & 0.66 & 2.43 & 14.34 & 12.09 \\
\hline EP3 & 1.41 & 0.14 & 3.21 & 13.22 & 14.31 \\
\hline EP4 & 1.21 & 0.17 & 4.48 & 15.96 & 16.42 \\
\hline EP5 & 1.72 & 0.56 & 4.00 & 14.28 & 13.95 \\
\hline EP6 & 1.69 & 0.50 & 4.30 & 13.81 & 15.83 \\
\hline EP7 & 1.49 & 0.49 & 5.86 & 18.56 & 16.10 \\
\hline EP8 & 2.06 & 0.71 & 2.58 & 14.11 & 14.66 \\
\hline EP9 & 1.32 & 0.12 & 5.52 & 15.37 & 16.11 \\
\hline WP1 & 2.11 & 0.52 & 3.33 & 14.44 & 10.41 \\
\hline WP2 & 2.49 & 0.64 & 3.54 & 13.43 & 13.36 \\
\hline WP3 & 2.63 & 0.51 & 4.08 & 13.88 & 18.38 \\
\hline WP4 & 2.58 & 0.78 & 4.99 & 15.08 & 17.10 \\
\hline WP5 & 2.07 & 0.73 & 3.70 & 16.01 & 16.35 \\
\hline WP6 & 1.82 & 0.46 & 2.45 & 14.57 & 16.47 \\
\hline WP7 & 2.04 & 0.73 & 2.76 & 14.89 & 14.04 \\
\hline WP8 & 1.38 & 0.61 & 2.60 & 16.06 & 12.92 \\
\hline WP9 & 1.45 & 0.48 & 2.98 & 19.31 & 15.02 \\
\hline Arithmetic mean & 1.82 & & 3.82 & 15.16 & 14.89 \\
\hline $\begin{array}{l}\text { Standard } \\
\text { deviation }\end{array}$ & 0.45 & & 1.17 & 1.63 & 1.94 \\
\hline C.V. $(\%)^{\mathrm{a}}$ & 24.76 & & 30.70 & 10.72 & 13.05 \\
\hline
\end{tabular}

$Q_{10}$ was calculated based on the daily average $\mathrm{CO}_{2}$ efflux and daily mean soil temperature at the $10 \mathrm{~cm}$ depth measured from June 1998 to August 1999.

${ }^{\text {a }}$ Coefficient of variation. 


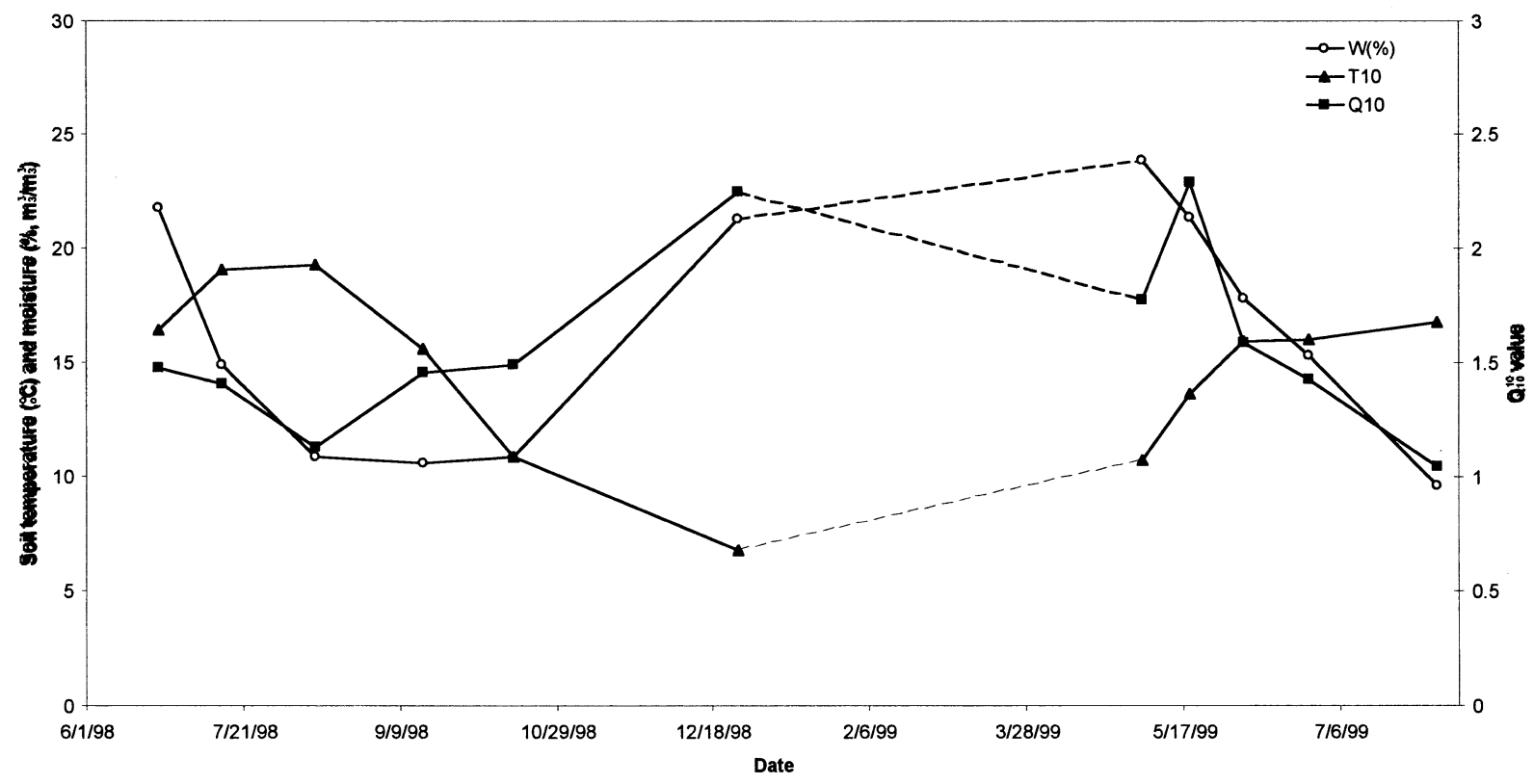

Fig. 5. Temporal variations in the value of $Q_{10}$, soil temperature (at the $10 \mathrm{~cm}$ depth), and soil volumetric moisture in a young ponderosa pine plantation in Northern California from June 1998 to August 1999. $Q_{10}$ (solid square) generally followed the pattern of the soil moisture (circle), except in May, 1999. However, an opposite pattern was observed for soil temperature except in May, 1999. These patterns demonstrate the correlation of $Q_{10}$ with soil temperature (negative) and moisture (positive) as shown in Eq. (10).

Table 2

List of soil respiration equations and parameters in some major ecosystem models

\begin{tabular}{lllll}
\hline Model & Equation & $Q_{10}$ & $q$ & Reference \\
\hline TEM & $f(T)=Q_{10}^{\frac{T}{10}}$ & 2 & 0.0693 & Raich et al. (1991) \\
Biome-BGC & $f(T)=\frac{T-25}{10}$ & $2 / 2.4$ & $0.0693 / 0.0875$ & Running and Hunt (1993) \\
Hadley Center & $f(T)=\frac{T-25}{Q_{10}^{10}}$ & $2 / 2.4$ & $0.0693 / 0.0875$ & Cox (2001) \\
CASA & $f(T)=\frac{T-30}{Q_{10}^{10}}$ & 2 & 0.0693 & Potter et al. (1993) \\
Heimann et al. & $f(T)=Q_{10}^{\frac{T}{10}}$ & 1.5 & 0.0693 & Heimann et al. (1989) \\
\hline
\end{tabular}

values used in these models. We now examine how such treatment affects the predictions of ecosystem carbon fluxes from these models, and what these differences imply in terms of terrestrial ecosystem carbon budget in response to global climate change.

A $Q_{10}$ value of 2 , corresponding to $q=0.0693$, commonly has been used in ecosystem models that simulate carbon dynamics over large geo- graphic areas. In this case, $Q_{10}$ completely ignores the spatial heterogeneity and temporal variability of the temperature sensitivity. Let us assume for now that a regional or global average of $Q_{10}$ can be derived and justified. Even so, we must ask: What would be the impact of variations in the average value of $Q_{10}$ on soil respiration estimates? How does this variability in temperature sensitivity of soil respiration affect the assessment of the 
carbon source-sink relationship at the regional and global scales?

First, let us consider the TEM (Raich et al., 1991) and CASA (Potter et al., 1993) models. From the temperature term of the soil respiration equations used in these models, $f(T)$, we can derive the rate of change in $f(T)$ with respect to the temperature sensitivity, $\mathrm{d} f / \mathrm{d} q$. For TEM, $\mathrm{d} f /$ $\mathrm{d} q=f(T) 10 T, \quad$ and for CASA, $\mathrm{d} f / \mathrm{d} q=$ $f(T) 10(T-30)$. When $T<30{ }^{\circ} \mathrm{C}$, this means that one unit increase in $q$ will result in an increase in $f(T)$ by $10 T$ times for TEM, but a decrease in $f(T)$ by $10(30-T)$ times for CASA. If we let $T=15{ }^{\circ} \mathrm{C}$ and change $Q_{10}$ from 2 to 2.1 (a $5 \%$ change), the estimated soil respiration will increase by $7.6 \%$ based on TEM, but decrease by $7.1 \%$ based on CASA. Similar differences also exist between TEM and Biome-BGC. Such diverging responses to changes in the temperature sensitivity are due largely to the different reference temperatures used in the models. A reference temperature of $0{ }^{\circ} \mathrm{C}$ is used in TEM and the Heimann's model, whereas 25 and $30{ }^{\circ} \mathrm{C}$ are used in Biome-BGC and CASA, respectively.

However, these differences may lead to drastically different estimates of ecosystem carbon fluxes at large spatial scales. For example, based on three ecosystem process models (Biome-BGC, Century, and TEM), Schimel et al. (2000) estimated that the conterminous USA was a net carbon sink during the period from 1980 to 1993, taking up $0.08 \mathrm{Pg} \mathrm{C} \mathrm{yr}^{-1}$ on average. This was in contrast with some previous estimates (Fan et al., 1998; Brown and Schoeder, 1999). This estimated carbon sink can turn into a net carbon source if the uncertainty of temperature sensitivity of soil respiration $(q)$ is considered. Heterotrophic respiration of the conterminous USA is estimated to be $3.37 \mathrm{Pg} \mathrm{C} \mathrm{yr}^{-1}$, equal to the average annual NPP calculated by the three models (Biome-BGC, Century, and TEM; VEMAP members, 1995). The mean annual temperature used in these models is $11.4{ }^{\circ} \mathrm{C}$ (Tian et al., 1999). Using the equation in TEM (Table 2), we find that heterotrophic respiration increases by $0.19 \mathrm{Pg} \mathrm{C} \mathrm{yr}^{-1}$ when $Q_{10}$ increases from 2.0 to 2.1. This suggests that a $5 \%$ change in $Q_{10}$ turns the conterminous USA into a net carbon source (releasing $0.11 \mathrm{Pg} \mathrm{C} \mathrm{yr}^{-1}$ ). If a
$Q_{10}$ value of 2.4 is used as in BIOME-BGC, the heterotrophic respiration will increase by 0.78 $\mathrm{PgC}_{\mathrm{yr}}^{-1}$. In contrast to the TEM result, the CASA model predicts that an increase in $Q_{10}$ from 2.0 to 2.1 results in a decrease of heteotrophic respiration by $0.15 \mathrm{Pg} \mathrm{C} \mathrm{yr}^{-1}$, tripling the estimate by Schimel et al. (2000). Again, the discrepancies between these two ecosystem models are due largely to the different reference temperatures. Biome-BGC uses a reference temperature of $20{ }^{\circ} \mathrm{C}$ for maintenance respiration and $25{ }^{\circ} \mathrm{C}$ for heterotrophic respiration, whereas TEM uses $0{ }^{\circ} \mathrm{C}$ as the reference temperature for both maintenance and heterotrophic respiration. Evidently, the effects of variations in $Q_{10}$ on the estimation of ecosystem carbon fluxes are significant, and the diverging responses among these ecosystem models seem to bring their validity for assessing the terrestrial carbon balance into question.

\section{Discussion and conclusions}

Variations in temperature sensitivity of soil respiration in response to climatic change are of particular importance to the transient models (Tian et al., 1999; Cox et al., 2000). The temperature sensitivity is likely to change as temperature and moisture change over time. In particular, as the climate becomes warmer, the temperature sensitivity is likely to decrease because of the negative correlation between $q$ and $T$. However, the effect of soil moisture is more complex. Assuming that the effects of soil temperature and moisture are negatively correlated as our field measurements have shown (Xu and $\mathrm{Qi}, 2001 \mathrm{~b})$, we expect that the relationship represented by Eq. (10) holds in general. Thus, soil moisture would be positively correlated with the temperature sensitivity of soil respiration.

The global temperature is predicted to increase by possibly $5-8{ }^{\circ} \mathrm{C}$ in the next century (IPCC, 2001). Soil moisture in summer is expected to decrease in most parts of the world, especially in mid- and high latitudes, despite the anticipated increase in global precipitation with global warming (Dai et al., 2001a,b). First, the increased pre- 
cipitation is expected to fall mainly in winter $\left(0-0.5 \mathrm{~mm} \mathrm{~d}^{-1}\right)$ in the high latitude regions (Dai et al., 2001a,b). Because much of the excess precipitation can be lost through surface runoff, it would have little effect on summer soil moisture. Second, summer temperature and hence evapotranspiration are expected to increase. It is predicted that summer soil moisture will decrease by 3-6\% over Eastern Europe, Western Asia, and much of Canada and by $10-20 \%$ in the low latitudes $\left(30^{\circ} \mathrm{S}-30^{\circ} \mathrm{N}\right)$ from 1990 to 2090 according to recent simulations by the NCAR Climate System Model. Future global warming seems to be accompanied by drier summer soils as predicted by general circulation models (Dai et al., 2001a,b).

The effects of soil temperature and moisture on $Q_{10}$ may have broader implications for understanding the feedback mechanisms of global warming and its impact on soil carbon balance. Although it is believed that soil carbon emission may be enhanced by the global warming for its temperature effect (Billings et al., 1982; Schleser, 1982; Raich and Schlesinger, 1992; Kirschbaum, 1995), it is possible that the presumed enhancement of soil respiration may be offset by the soil moisture effect as shown in our results. The overall effect can only be adequately evaluated by treating the temperature sensitivity measure as a function of, at least, temperature and moisture. The incorporation of such a dynamic temperature sensitivity measure is more likely to lower the estimate of soil carbon emission. Based on our study, both higher temperature and lower moisture may reduce the value of $Q_{10}$, and hence soil respiration.

Even a small change in $Q_{10}$ may result in a large difference in estimated soil respiration because of the nonlinear nature of the $Q_{10}$ relationship. According to our results $1{ }^{\circ} \mathrm{C}$ increase in soil temperature at $10 \mathrm{~cm}$ depth will reduce the $Q_{10}$ value by 0.084 (Fig. 4). Assuming the global annual $\mathrm{CO}_{2}$ flux from soil is $68 \mathrm{PgC}$ (Raich and Schlesinger, 1992) and the $Q_{10}$ value is 2 at a mean annual temperature of $15^{\circ} \mathrm{C}$, the temperature effect on $Q_{10}$ almost cancels the effect of the temperature increase by $1{ }^{\circ} \mathrm{C}$ on the global annual $\mathrm{CO}_{2}$ flux as predicted using the constant $Q_{10}$ of 2. Reducing soil moisture content will also decrease the temperature sensitivity of soil respiration, especially, in the arid and semi-arid regions. According to our study, $1 \%$ decrease in soil volumetric moisture will reduce the $Q_{10}$ value by 0.08 , which will cause a significant reduction in soil respiration.

In conclusion, the temperature sensitivity of soil respiration is in general a function of soil temperature, moisture and other factors. However, many ecosystem models have treated it as a constant. This oversimplification not only affects the accuracy of estimates of the net ecosystem carbon fluxes, but also is responsible for the discrepancy in predictions among different ecosystem models. The dependence of the temperature sensitivity on multiple factors has important implications for modeling ecosystem responses to climatic changes and, particularly, the terrestrial carbon balance. Because of the effect of temperature and moisture on the temperature sensitivity, soil respiration may increase less profoundly in response to global warming. Current global ecosystem models tend to overestimate soil respiration by using a constant $Q_{10}$, which exaggerates the temperature sensitivity and ecosystems responses to future a warmer climate.

\section{Acknowledgements}

We thank Bob Heald, David Rambeau, Sheryl Rambeau, Wenzhi Zhao, Chang Che, Yan Chen, Terry DeBiase, Jianwu Tang, and Qinghua Guo for their assistance in field data collection, and Dennis Baldocchi, Shuijin Hu, Mingkui Cao and Terry DeBiase for their comments on a draft of this paper. We are grateful to Sierra Pacific Industries for the permission to conduct the study on their forestland. Funding for this research project was provided by USDA Agricultural Experimental Station (AES) and University of California, through an AES grant and Academic Senate Committee on Research (COR) grant. YQ also acknowledges the Cheong Kong Endowment Program administered by the Ministry of Education of China for additional support. JW was supported in part by US EPA grant R827676-01-0 and US NSF grant DEB 97-14833 (CAP-LTER). 


\section{References}

Betts, R.A., 2000. Offset of the potential carbon sink from boreal forestation by decrease in surface albedo. Nature 408, 187-190.

Billings, W.D., Luken, J.O., Mortensen, D.A., Peterson, K.M., 1982. Arctic tundra: a source or sink for atmospheric carbon dioxide in a changing environment? Oecologia 53, $7-11$.

Brown, S.L., Schoeder, P.E., 1999. Spatial patterns of aboveground production and mortality of woody biomass for eastern US forests. Ecol. Appl. 9 (3), 968-980.

Carlyle, J.C., Than, U.B., 1988. Abiotic controls of soil respiration beneath an eighteen-year-old Pinus radiata stand in south-eastern Australia. J. Ecol. 76, 654-662.

Cox, P.M., 2001. Description of the TRIFFID dynamic global vegetation model. Hadley Centre Technical Note, Number 24.

Cox, P., Betts, R.A., Jones, C.D., Spall, S.A., Totterdell, I.J., 2000. Acceleration of global warming due to carbon-cycle feedbacks in a coupled climate model. Nature 408, 184187.

Dai, A., Wigley, T.M.L., Boville, B.A., Kiehl, J.T., Buja, L.E., 2001a. Climates of the 20th and 21st centuries simulated by the NCAR Climate System Model. J. Climate 14, 485-519.

Dai, A., Meehl, G.A., Washington, W.M., Wigley, T.M.L., Arblaster, J.A., 2001b. Ensemble simulation of 21st century climate changes: business as usual vs. CO2, Bull. Am. Met. Sco. 82, 2377-2388.

Davidson, E.A., Belk, E., Boone, R.D., 1998. Soil water content and temperature as independent or confounded factors controlling soil respiration in a temperate mixed hardwood forest. Glob. Change Biol. 4, 217-227.

Fan, S.M., Gloor, M., Mahlman, J., Pacala, S., Sarmiento, J., Takahashi, T., Tans, P., 1998. A large terrestrial carbon sink in North America implied by atmospheric and oceanic carbon dioxide data and models. Science 282, 442-446.

Gulledge, J., Schimel, J.P., 2000. Controls on soil carbon dioxide and methane fluxes in a variety of Taiga forest stands in interior Alaska. Ecosystems 3, 269-282.

Heimann M., Keeling C.D., Tucker C.J., 1989. A three-dimensional model of atmospheric $\mathrm{CO}_{2}$ transport based on observed winds: 3 . Seasonal cycle and synoptic timescale variations. In: Peterson, D.H., (Ed.), Aspect of Climatic Variability in the Pacific and the Western Americas, Geophys. Monogr., no 55, American Geophysical Union,Washington D.C., pp. 277-303.

Holland, E.A., Townsend, A.R., Vitousek, P.M., 1995. Variability in temperature regulation of $\mathrm{CO}_{2}$ fluxes and $\mathrm{N}$ mineralization from five Hawaiian soils: implication for a changing climate. Glob. Change Biol. 1, 115-123.

Kirschbaum, M.U.F., 1995. The temperature dependence of soil organic matter decomposition, and the effect of global warming on soil organic C storage. Soil Biol. Biochem. 27, $753-760$.

Kirschbaum, M.U.F., 2000. Will changes in soil organic carbon act as a positive or negative feedback on global warming? Biogeochemistry 48, 21-51.
Kutsch, W.L., Kappen, L., 1997. Aspects of carbon and nitrogen cycling in soils of the Bornhoved Lake district. II. Modeling the influence of temperature increase on soil respiration and organic carbon content in arable soils under different managements. Biogeochemistry 39, 207224.

Lloyd, J., Taylor, J.A., 1994. On the temperature dependence of soil respiration. Functional Ecol. 8, 315-323.

Nicolis, G., Prigogine, I., 1989. Exploring Complexity: An Introduction. W.H. Freeman and Company, New York.

Potter, C.S, Randerson, J.T., Field, C.B., Matson, P.A., Vitousek, P.M., Mooney, H.A., Klooster, S.A., 1993. Terrestrial ecosystem production: a process model based on global satellite and surface data. Glob. Biogeochem. Cycl. 7, 811-841.

Raich, J.W., Schlesinger, W.H., 1992. The global carbon dioxide flux in soil respiration and its relationship to vegetation and climate. Tellus 44B, 81-99.

Raich, J.W., Rastetter, E.B., Melillo, J.M., Kicklighter, D.W., Steudler, P.A., Peterson, B.J., Grace, A.L., Moore, B. III, Vörösmarty, C.J., 1991. Potential net primary productivity in South America: application of a global model. Ecol. Appl. 1, 399-429.

Running, S.W., Hunt, E.R. Jr., 1993. Generalization of a forest ecosystem process model for other biomes, BIOMEBGC, and an application for global-scale models. In: Ehleringer, J.R., Field, C. (Eds.), Scaling Processes Between Leaf and Landscape Levels. Academic Press, Orlando, pp. $141-158$.

Schimel, D., Melillo, J., Tian, H., McGuire, A.D., Kicklighter, D., Kittel, K., Rosenbloom, N., Running, S., Thornton, P., Ojima, D., Parton, W., Kelly, R., Sykes, M., Neilson, R., Rizzo, B., 2000. Contribution of increasing $\mathrm{CO}_{2}$ and climate to carbon storage by ecosystems in the United States. Science 287, 2004-2006.

Schleser, G.H., 1982. The response of $\mathrm{CO}_{2}$ evolution from soils to global temperature changes. Zeitschrift fur Naturforschung 37a, 287-291.

Simmons, J.A., Fernandez, I.J., Briggs, R.D., Delaney, M.T., 1996. Forest floor carbon pools and fluxes along a regional climate gradient in Maine, USA. For. Ecol. Manag. 84, $81-95$.

Singh, J.S., Gupta, S.R., 1977. Plant decomposition and soil respiration in terrestrial ecosystems. Bot. Rev. 43, 449528.

Thierron, V., Laudelout, H., 1996. Contribution of root respiration to total $\mathrm{CO}_{2}$ efflux from the soil of a deciduous forest. Can. J. For. Res. 26, 1142-1148.

Tian, H., Melillo, J.M., Kicklighter, D.W., McGuire, A.D., Helfrich, J., 1999. The sensitivity of terrestrial carbon storage to historical climate variability and atmospheric $\mathrm{CO}_{2}$ in the United States. Tellus 51B, 414-452.

Townsend, A.R., Vitousek, P.M., Holland, E.A., 1992. Tropical soils could dominate the short-term carbon cycle feedbacks to increased global temperatures. Clim. Change 22, $293-303$.

Van't Hoff, J.H., 1898. Lectures on theoretical and physical 
chemistry. Part I. Chemical dynamics (translated by R. A. Lehfeldt), Edward Arnold, London., pp. 224-229.

VEMAP members, 1995. Vegetation/Ecosystem modeling and analysis project: comparing biogeography, and biogeochemistry models in a continental-scale study of terrestrial ecosystem responses to climate change and $\mathrm{CO}_{2}$ doubling. Glob. Biogeochem. Cycl. 4, 407.

Wu, J., Loucks, O.L., 1995. From balance-of-nature to hierarchical patch dynamics: a paradigm shift in ecology. Q. Rev. Biol. 70, 439-466.
Wu, J., 1999. Hierarchy and scaling: extrapolating information along a scaling ladder. Can. J. Rem. Sens. 25, 367380.

Xu, M., Qi, Y., 2001a. Soil surface $\mathrm{CO}_{2}$ efflux and its spatial and temporal variation in a young ponderosa pine plantation in California, Glob. Change Biol. 7, 667-677.

Xu, M., Qi, Y., 2001b. Spatial and seasonal variations of $Q_{10}$ determined by soil respiration measurements at a Sierra Nevadan forest. Glob. Biogeochem. Cycl. 15 (3), 687-697. 